\title{
Formation and stabilisation in water of metal nanoparticles by a hyperbranched polymer chemically analogous to PAMAM dendrimers.
}

Nelly Pérignon, Anne-Françoise Mingotaud, Jean-Daniel Marty*, Isabelle Rico-Lattes and Christophe Mingotaud

Laboratoire IMRCP, UMR CNRS 5623, Université Paul Sabatier, 118 route de Narbonne, 31062 Toulouse, France.

\section{Supporting data.}

Characterizations. ${ }^{1} \mathrm{H}$ NMR spectra were recorded on a Bruker AC 250 spectrometer at 250.13 MHz and on a Bruker ARX 400 at 400.13 MHz. ${ }^{13} \mathrm{C}$ NMR spectra were recorded on a Bruker Avance 300 spectrometer at $75.47 \mathrm{MHz}$ and on a Bruker ARX 400 at $100.61 \mathrm{MHz}$. Attribution of the signals was made by COSY, HSQC and HMBC experiments and comparison with corresponding spectra of PAMAM dendrimers. Quantitative ${ }^{15} \mathrm{~N}$ NMR was carried out on a Bruker AMX400 at $40.55 \mathrm{MHz}$ with a delay between pulses of $100 \mathrm{~s}$ (probehead for $10 \mathrm{~mm}$ tubes, $30^{\circ}$ pulse of $20 \mu \mathrm{s}$, inverse-gated proton decoupled experiments). Quantitative ${ }^{13} \mathrm{C}$ NMR was carried out with a delay between pulses of 55s and NOE was eliminated. The quantitative response was checked with a test solution of known concentrations of $\mathrm{Me}_{4} \mathrm{NOH}$ and ethylenediamine. The average molecular weight of the polymers was determined by size exclusion chromatography (SEC) analysis in carbonate buffer solution at $\mathrm{pH} 10$ (flow rate $0.5 \mathrm{~mL} / \mathrm{min}$ ) on an apparatus equipped with a Waters refractive index detector, a Waters column pack (Shodex OHpak SB-802HQ, SB-802.5HQ, SB-804HQ) and a Minidawn Wyatt light scattering detector. The refractive index increments for PAMAM dendrimers were measured in the same eluent at ambient temperature and was 
found equal to $\mathrm{dn} / \mathrm{dc}=0.175\left(\mathrm{~mL} \cdot \mathrm{g}^{-1}\right)$. The values for the hyperbranched polyamides were assumed to be identical. Considering the fact that these polymers have been observed to trap some solvent, even after prolonged drying under vacuum, the accuracy for the molecular weight measurement is estimated around $20 \%$.

Specimens for TEM observations were prepared by placing a drop of an aqueous solution of coated nanoparticules on a holey-carbon-coated grid. TEM images were obtained on a Philips CM12 microscope.

Reagents. Tris(2-aminoethyl)amine (Aldrich) was distilled under reduced pressure and store under argon atmosphere before use. Tris(2-di(methylacrylate)aminoethyl)amine was synthesized according to the method of Dvornic (reference 5) and ${ }^{1} \mathrm{H}$ and ${ }^{13} \mathrm{C}$ NMR data were in accordance with the literature. All other products (including PAMAM dendrimers) were obtained from Aldrich and used without purification.

Synthesis. For HYPAM4, 2.5g of tris(2-aminoethyl)amine $(17.1 \mathrm{mmol})$ were mixed with $1.13 \mathrm{~g}$ of tris(2-di(methylacrylate)aminoethyl)amine $(1.7 \mathrm{mmol})$. The solution was stirred under argon at $75^{\circ} \mathrm{C}$ during two days, at which time the products were dissolved in $5 \mathrm{~mL}$ $\mathrm{CH}_{2} \mathrm{Cl}_{2}$ and precipitated into $200 \mathrm{~mL}$ THF at $0^{\circ} \mathrm{C}$. $2.05 \mathrm{~g}$ of precipitated polymer was obtained as a yellow gum. ${ }^{1} \mathrm{H}$ NMR $\left(\mathrm{CDCl}_{3}, 200.15 \mathrm{MHz}\right)$ : 2.1-2.9 (m, $\mathrm{NH}_{2},-\mathrm{CH}_{2}-\mathrm{NH}_{2}$, $\mathrm{CH}_{2}$-CO-); 3.25 (br m, - $\mathrm{CH}_{2}-\mathrm{NHCO}$ ); 8.29 (br s, -NHCO-). ${ }^{1} \mathrm{H}$ NMR ( ${ }_{2} \mathrm{O}, 400.13 \mathrm{MHz}$ ): 2.34 (m, - $\left.\mathrm{CH}_{2}-\mathrm{CO}-\right) ; 2.5$ (m, N-CH$\left.-\mathrm{CH}_{2}-\mathrm{N}\right) ; 2.55$ (m, $\left.\mathrm{CONH}_{2}-\mathrm{CH}_{2}-\mathrm{CH}_{2}-\mathrm{N}\right) ; 2.63$ (m, $\left.\mathrm{CH}_{2}-\mathrm{NH}_{2}\right) ; 2.73$ (m, N-CH$\left.-\mathrm{CH}_{2}-\mathrm{CO}\right) ; 3.22$ (m, $\left.-\mathrm{CH}_{2}-\mathrm{NHCO}-\right) ;{ }^{13} \mathrm{C}$ NMR $\left(\mathrm{D}_{2} \mathrm{O}\right.$, 75.47MHz): 32.735 .7 (- $\left.\mathrm{CH}_{2}-\mathrm{CO}\right) ; 36.9$ (- $\left.\mathrm{CH}_{2}-\mathrm{NH}-\mathrm{CO}-\right) ; 37.9\left(-\mathrm{CH}_{2}-\mathrm{NH}_{2}\right) ; 49.3\left(\mathrm{~N}-\mathrm{CH}_{2}-\right.$ $\left.\mathrm{CH}_{2}-\mathrm{CO}\right) ; 50.051 .452 .5\left(\mathrm{CONH}-\mathrm{CH}_{2}-\mathrm{CH}_{2}-\mathrm{N}\right) ; 56.0\left(\mathrm{~N}-\mathrm{CH}_{2}-\mathrm{CH}_{2}-\mathrm{N}\right) ; 174.7(\mathrm{CONH})$. 


\section{Polymer and dendrimer characterization}

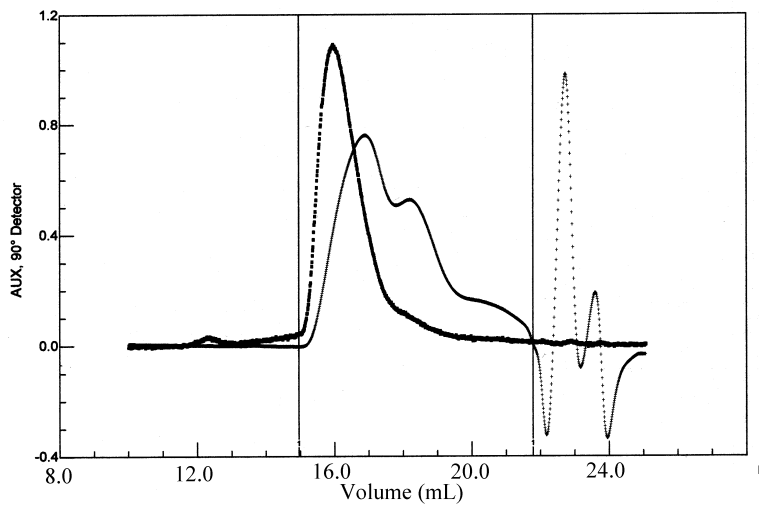

Figure 1. Typical SEC chromatogram for HYPAM (bold line: light-scattering detection, regular line: refractometry detection)

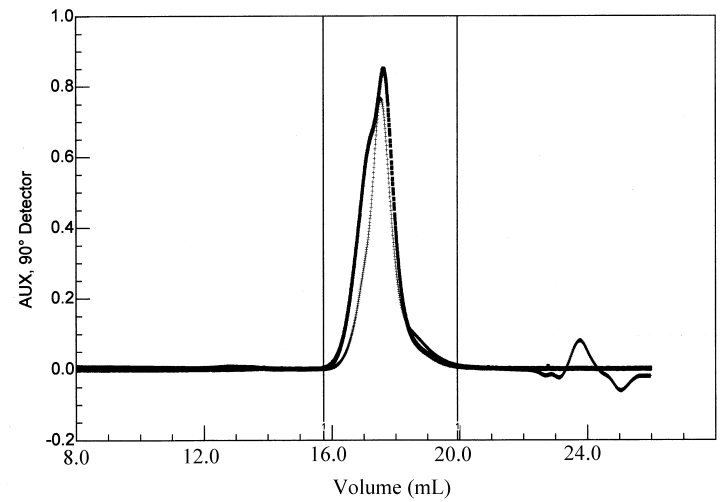

Figure 2. PAMAM4 SEC chromatogram (bold line: light-scattering detection, regular line: refractometry detection)

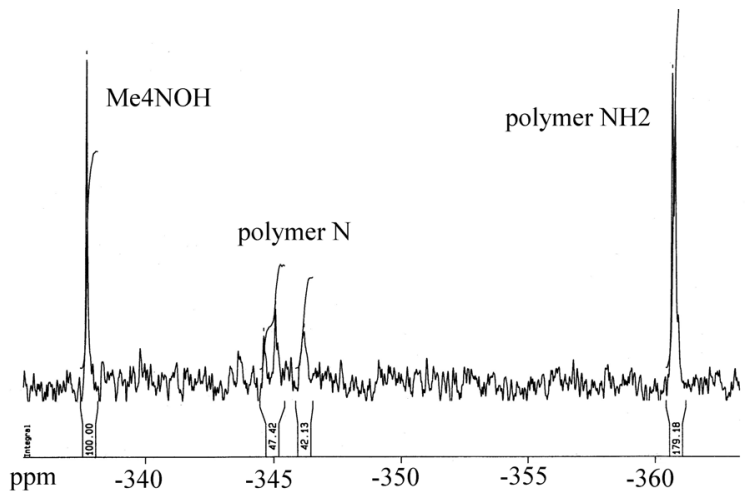

Figure 3. Titration of amine groups by quantitative ${ }^{15} \mathrm{~N}$ NMR 


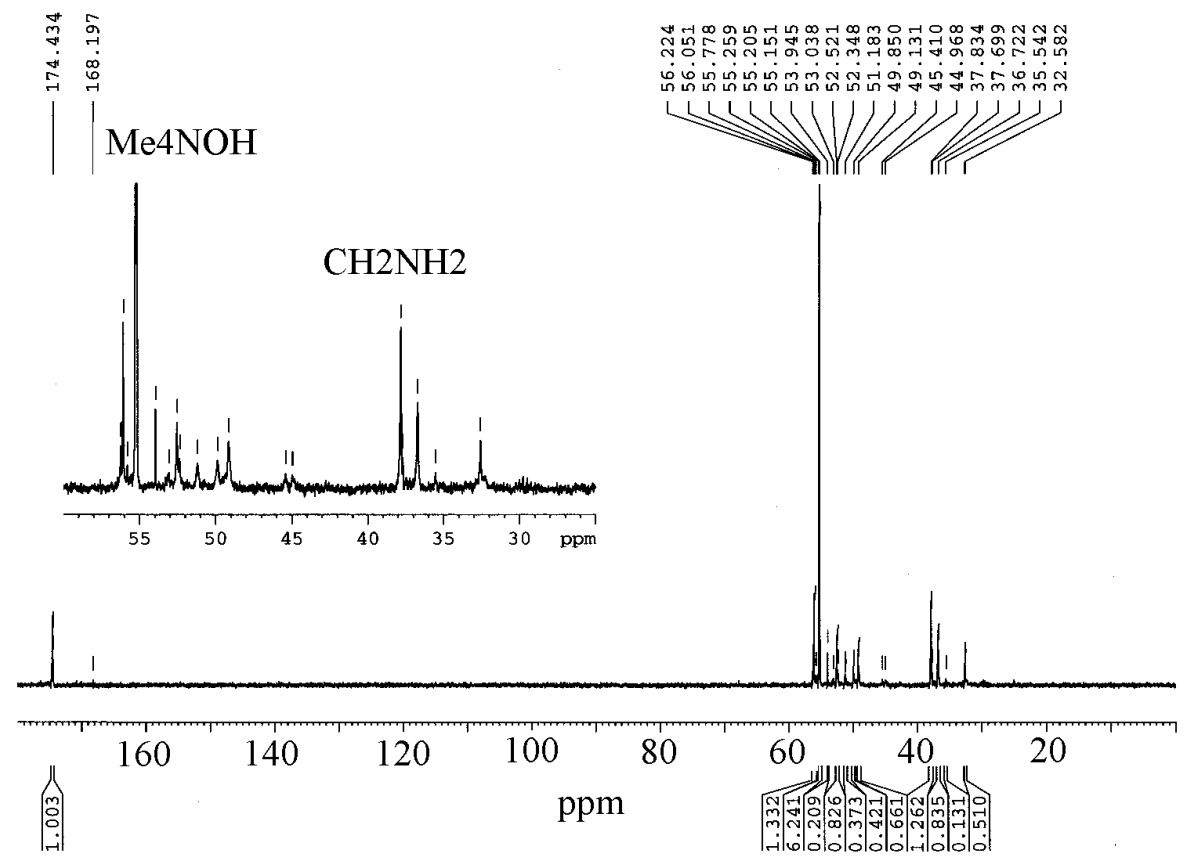

Figure 4. Titration of functional groups by ${ }^{13} \mathrm{C}$ NMR. 